\title{
Avaliação em larga escala e qualidade: dos enquadres regulatórios aos caminhos alternativos
}

Ivan Amaro

Universidade do Estado do Rio de Janeiro

\section{Resumo}

As avaliações em larga escala consolidam-se como "coluna vertebral" da busca pela qualidade da educação básica, utilizando-se de testes aplicados nacionalmente, priorizando o desempenho cognitivo dos estudantes. O objetivo deste artigo é discutir as implicações que estas avaliações têm provocado no cotidiano escolar. A partir de uma abordagem qualitativa, apresentamos aqui alguns captados em uma escola de Duque de Caxias e outra de Nova Iguaçu, redes municipais de educação localizadas na Baixada Fluminense-RJ. Os achados indicam um contexto de ambiguidades nas escolas: redução curricular, práticas neotecnicistas, responsabilização de professores, foco em resultados.

Palavras-chave: Avaliação em larga escala. Qualidade. Regulação. Performatividade. Responsabilização. 


\section{Assessment in large scale and quality: the alternative ways to regulatory framings}

The large-scale assessments are consolidated as "spine" of the prusuit of quality of basic education, using tests applied nationally, emphasizing the cognitive performance of students. The purpose of this article is to discuss the implications that these assessments have led to the school routine. From a qualitative approach, we present here some captured on a school Duque de Caxias and one of Nova Iguaçu, municipal education networks located in the Baixada Fluminense-RJ. The findings indicate a contexto of ambiguity in schools: curriculum reduction, neo technicalities practices, accountability of teachers, focus on results.

Keywords: Large-scale evaluation. Quality. Regulation. Performativity. Accountability.

\section{Evaluación en gran escala y calidad: desde los encuadres reguladoras a las formas alternativas}

Las evaluaciones a gran escala se consolidan como "columna vertebral" de la búsqueda de la calidad de la educación básica, mediante testes aplicados a nivel nacional, priorizando el rendimiento cognitivo de los estudiantes. El propósito de este artículo es discutir las implicaciones que estas evaluaciones ha llevado a la rutina escolar. Desde un enfoque cualitativo, presentamos aquí algunos capturados en una escuela de Duque de Caxias y uno de Nova lguaçu, redes de educación municipales ubicadas en la Baixada Fluminense-RJ. Los resultados indican un contexto de ambigüedad en las escuelas: reducción del currículo, practicas neotecnicistas, la rendición de cuentas de los docentes, centralización en resultados.

Palabras clave: Evaluación a gran escala. Calidad. Reglamento. La performatividad. Rendición de cuentas. 


\section{Avaliação em larga escala: uma "epidemia" em busca da qualidade?}

Sob a bandeira da retórica da qualidade, a avaliação em larga escala disseminouse nas estruturas públicas, com fortes delineamentos regulatórios, gerencialistas e de responsabilização. Para Veiga-Netto (2012), estes são tempos de "delírios avaliatórios". São tempos de "obsessão avaliativa" (Afonso, 2007), em que alguns modos de imputar responsabilidades à escola e a seus docentes, por meio de avaliações sistêmicas e estandardizadas, transformaram-se numa panaceia ou mesmo num fetiche.

Arrisco-me a afirmar que vivemos uma verdadeira "epidemia avaliativa", tendo em vista que os pressupostos ideológicos e pragmáticos das avaliações em larga escala têm sido replicados em quase a totalidade dos estados brasileiros e em muitos municípios. Parece-nos um tempo em que as avaliações em larga escala estão presentes nas redes e, no entanto, não atendem à finalidade de produzir informações para subsidiar o planejamento das políticas públicas. Percebe-se, cada vez mais, que elas assumiram papel central no cenário das políticas educacionais nos contextos local, nacional e internacional, sob o discurso de melhoria da qualidade da educação. Entretanto, cabem algumas problematizações sobre seus reais efeitos: que feições as avaliações em curso vêm assumindo no contexto da prática escolar? A quem interessam? Para que têm servido? Alinhada a estas perguntas, surge uma outra mais abrangente: de que visão de qualidade estas avaliações estão a serviço?

O marco detonador insere-se na reconfiguração geopolítica e no processo de reestruturação econômica global a partir de reformas iniciadas na década de 1980, mais detidamente a partir da Inglaterra e dos Estados Unidos. O discurso conservador neoliberal atravessou fronteiras e instalou-se como pensamento hegemônico sustentado na intenção de promover ampla modernização nas estruturas estatais dotando-as de "eficiência e excelência", à moda empresarial. Desde a segunda metade da década de 1990 que a avaliação em larga escala, no Brasil, intensifica-se e se impõe como motor na engrenagem educacional sob o pretexto de promoção da qualidade da educação em seus diversos níveis. Com significados, finalidades e funções distintas da ideia de educação como bem público, ela incorporou-se não só ao cotidiano escolar de professores e estudantes, como também, nas estruturas da administração pública, ressignificando-as e redimensionando-as.

Embora com características específicas, essas políticas seguem orientações internacionais que, segundo Afonso (2012) e Freitas (2012), envolvem: estratégias de prestação de contas (accountability) baseadas em resultados de testes padronizados de alto impacto (high-stakes testing); imputações negativas e punitivas às escolas e professores, caso não atinjam as metas estabelecidas centralizadamente; estreitamento dos currículos, focalizando-os em competências básicas e apagando 
outros conhecimentos; metodologias de ensino dirigidas à preparação para os exames; espírito competitivo entre professores e escolas; pressão para a melhoria dos resultados instituindo premiações e punições; precarização do trabalho docente.

Diversos estudos recentes (Sousa; Oliveira, 2010, Esquissani, 2010, Werle, 2011, Shiroma; Schneider, 2011) que tratam de suas repercussões e de seus impactos nas redes, na prática pedagógica, no currículo e no trabalho docente ganham maior visibilidade e já apontam consequências que as avaliações têm produzido no interior das redes e das escolas

As avaliações consolidam-se como "coluna vertebral" da busca pela qualidade, utilizando-se de testes aplicados nacionalmente, priorizando o desempenho cognitivo dos estudantes e, consequentemente, com objetivo de avaliar também o trabalho docente e das escolas. Este foco visa à ampliação do controle sobre as redes, sobre as escolas, sobre o trabalho docente e, em última instância, sobre o corpo discente para ajustá-lo aos princípios reestruturadores de mercado. Discutir e problematizar estas implicações no cotidiano escolar e no trabalho docente, com a esperança de melhorar a educação, é o objetivo deste artigo.

Neste artigo, apresentamos recortes de resultados de pesquisa ${ }^{1}$ desenvolvida no período de 2010 a 2014. Diante da problemática que situamos anteriormente, nossa compreensão sobre os caminhos a seguir na pesquisa não poderia ignorar a necessidade de estarmos próximos da realidade cotidiana do campo, ou seja, da escola. Neste sentido, estar no cotidiano das escolas nos permitiu presenciar situações diversas para relacioná-las aos resultados obtidos em avaliações externas e compreendê-las em contextos mais amplos e complexos que vão além dos meros números que definem ou não níveis de qualidade da educação. Assim, ancorarmos numa abordagem qualitativa nos proporcionou a descrição de acontecimentos, de processos para melhor entendermos como a escolas, professores e professoras são afetados/as pelas avaliações em larga escala. A pesquisa contou com a contribuição de bolsistas de Iniciação Científica e de Mestrado em seu desenvolvimento metodológico ${ }^{2}$, bem como no processo de coleta, sistematização e análise de dados. Inicialmente, o projeto previa a participação de cinco (05) municípios (Duque de Caxias, Nova Iguaçu, Mesquita, São João de Meriti e Nilópolis) localizados na Baixada Fluminense, Região Metropolitana do Rio de Janeiro (RMRJ).

1 Pesquisa "Observatório das Periferias Urbanas" - Observatório da Educação INEP/CAPES, contemplada pelo Edital 2010 de Fomento a Estudos e Pesquisas em Educação, Edital n 038/2010 INEP/CAPES. Um dos focos da pesquisa sustentava-se sobre as repercussões do IDEB e da Prova Brasil na escola, direcionando os olhares para as implicações dos resultados de Língua Portuguesa no currículo e na prática pedagógica. Relatório final foi encaminhada à CAPES em janeiro/2015.

2 O primeiro ano da pesquisa foi direcionado para a constituição da equipe: seleção de bolsistas, encaminhamentos de documentação, contato com as Secretarias Municipais de Educação, com as escolas e com professores/as participantes da pesquisa. Num segundo momento, nos anos de 2011, uma das ações constituiu-se da realização de estudos sobre Metodologias Qualitativas de Pesquisa em Educação com foco para a observação participantes, para entrevistas semiestruturadas e pelo trabalho com grupos focais. 
A primeira etapa nos colocou desafios diversos, pois tratava-se de promover a aproximação com as Secretarias Municipais de Educação (SMEs) para que tomassem conhecimento do projeto de investigação e contribuíssem, também, para os encaminhamentos acerca de sua realização. Após diversas tentativas de estabelecer uma agenda comum, somente no final do primeiro semestre de 2010 é que foi possível realizar as conversas iniciais com cada uma das secretarias para que tomassem conhecimento do escopo e dos objetivos da investigação e, ao mesmo tempo, sugerissem uma escola para participarem. Nestas conversas, os critérios de escolha das escolas foram seguindo as próprias preocupações dos gestores locais. Dentre estas preocupações encontrava-se um conjunto de indagações que se situavam sobre os motivos de algumas escolas não conseguirem obter os resultados satisfatórios. Esclarecemos que não se tratava de uma pesquisa comparativa, mas de uma pesquisa que buscasse compreender as implicações dessas avaliações no cotidiano da escola, identificando aspectos que não eram captáveis pelos testes e que poderiam ajudar na definição de políticas de formação continuada, bem como no planejamento das ações pedagógicas no âmbito do município. As secretarias ficaram responsáveis por indicar as escolas. Entretanto, apenas os municípios de Duque de Caxias e Nova Iguaçu prontamente se colocaram para participação na pesquisa e encaminharam as escolas participantes. Realizamos uma reunião com representantes das duas SMEs e com as diretoras e orientadoras pedagógicas das escolas indicadas ${ }^{3}$.

Como parte da segunda etapa da pesquisa, o período de agosto a dezembro de 2010 ficou destinado para que as bolsistas visitassem as escolas, quinzenalmente, para coletar informações junto à direção e à orientação pedagógica sobre a estrutura, a comunidade, o corpo docente e discente de cada uma das escolas. Foram designadas para as escolas de cada município, uma dupla de bolsistas. Ao longo dos anos de $2011^{4}$ e 2012 , foram realizadas observações participantes e entrevistas com docentes e equipe gestora de cada uma das escolas como forma de acompanhar as ações desenvolvidas pelas mesmas e que indicassem relações com as avaliações externas, especificamente, a Prova Brasil, por se tratar de escolas que atendem à educação infantil e ao primeiro segmento do ensino fundamental ( $1^{\circ}$ ao $5^{\circ}$ ano).

Duque de Caxias $^{5}$ é uma cidade de contrastes. Apesar de ter o $2^{\circ}$. maior $\mathrm{PIB}^{6}$

3 Foram indicadas 2 escolas de cada município. Para este artigo, porém, apresentamos apenas os dados de uma escola de cada município.

4 Este ano foi relevante tendo em vista a aplicação da Prova Brasil no mês de novembro. As bolsistas acompanharam todo o processo de preparação, de tensão, de expectativa, bem como da aplicação dos testes de Língua Portuguesa e Matemática aos alunos do $5^{\circ}$ ano de escolaridade do Ensino Fundamental.

5 O município localiza-se numa região denominada Baixada Fluminense, com uma área de aproximadamente 2.800 $\mathrm{Km}^{2}$, conhecidamente como uma das regiões mais pobres e violentas do país

6 Segundo dados do Censo 2010 (IBGE), o PIB de Duque de Caxias aferido foi de R\$32.266.476,00; atrás apenas 
(Produto Interno Bruto) do Rio de Janeiro, o município não oferece serviços básicos de qualidade à população: precária oferta de água e coleta de esgoto ${ }^{7}$, parcos investimentos na saúde, na educação, nos transportes, na infraestrutura da cidade (CRUZ, 2012; BERNARDES, 2007; ENNE, 2004).

As taxas de aprovação, desde 2005, nos anos de realização da Prova Brasil, apresentam-se estagnados, sem avanços significativos. Apesar dos objetivos do Saeb (Sistema de Avaliação da Educação Básica) indicarem como finalidade subsidiar os sistemas para redefinição de suas políticas, há indicações de que as informações produzidas ainda não se traduzem em melhoria substantiva do sistema.

A Escola DC, de Duque de Caxias, foi indicada pela SME por considerar que a escola, desde o início das avaliações, em 2005, apresentava baixo Ideb e foi diminuindo nos anos de 2007 e 2009'. Em 2011, entretanto, a escola obteve o maior Ideb da região metropolitana do Rio de Janeiro. Até então, não tinha atingido nenhuma das metas estabelecidas. Ao observarmos as informações que compõem o Ideb, percebemos que os dados de aprovação estavam abaixo da média do município e, por isso, a escola não atingiu as metas traçadas. Em 2007, a escola apresentava $81 \%$ de aprovação. No ano de 2009 , há uma queda expressiva: a aprovação cai para $68 \%$. No ano de 2011, porém, há uma virada e a escola atinge seu maior índice em cinco anos: $89 \%$, o que parece decisivo para o aumento surpreendente do Ideb para 6,6. É importante frisar que a escola está localizada numa região bastante violenta e próxima a uma comunidade controlada pelo tráfico de drogas (Vila Nova, denominada como "Lixão"), o que indica enormes dificuldades de sua gestão e de seu corpo docente para oferecerem uma educação de qualidade. Atende a, aproximadamente, 300 crianças da educação infantil ao $5^{\circ}$ ano do ensino fundamental, em dois turnos (de $7 \mathrm{~h}$ às $11 \mathrm{~h}$ e de $12 \mathrm{~h}$ às $16 \mathrm{~h}$ ) ${ }^{10}$. A escola conta com um corpo docente de 13 professoras (Graduadas, 10 possuem Pós-Graduação, sendo que uma delas possui Mestrado), um Diretor e duas Orientadoras (Pedagógica e Educacional). Desse contingente, 3 professoras, além das contribuições do Diretor e das Orientadoras Pedagógica e Educacional, aceitaram participar da pesquisa, principalmente, por

do Rio de Janeiro, capital do Estado, que foi de $R \$ 154.777 .301,00$. Sua população gira em torno de 855.000 pessoas, com quase $0,5 \%$ vivendo em área rural, o que configura um grande conglomerado espaço urbano. A estimativa para 2015 é de 882.729 habitantes. Conta com uma rede escolar municipal composta por 142 escolas, com 62.928 matrículas no ensino fundamental e 6.670 matrículas na pré-escola, possui cerca de 2.500 docentes

7 Estudo divulgado pela organização não governamental Trata Brasil coloca Duque de Caxias entre os dez municípios do país com mais de 300 mil habitantes com os piores índices de coleta e tratamento de esgoto. Disponível em: http://agenciabrasil.ebc.com.br/noticia/2012-05-01/um-dos-15-municipios-mais-ricos-do-paisduque-de-caxias-e-antiexemplo-na-area-de-saneamento, acesso em 05/08/2013

8 Censo Escolar 2005 a 2011.

9 O Ideb alcançado em 2005 foi de 3,5; em 2007 foi de 3,3 e em 2009 foi de 2,8. Em 2011, saltou para 6,6.

${ }^{10} \mathrm{O}$ segundo turno atende num horário diferenciado, justamente por que após as 16 horas, há uma grande movimentação característica dos componentes do tráfico, o que torna mais vulnerável qualquer movimentação de crianças, professoras, funcionários da escola. 
atuarem diretamente com as turmas de $5^{\circ}$ ano, que são alvo, bianualmente, das avaliações externas - Prova Brasil.

Nova Iguaçu ${ }^{11}$ é a segunda cidade mais populosa da Baixada Fluminense, atrás, apenas, de Duque de Caxias. A Escola NI foi indicada pela SME por apresentar bons resultados no Ideb desde 2007, atingindo as metas estabelecidas pelo MEC. Em 2007, apresentava Ideb 4,1; em 2009, 4,7; em 2011 aumentou para 5,0 e manteve o mesmo índice em 2013. A escola atende a, aproximadamente, 170 alunos distribuídos em 2 turnos diários. Possui uma Diretora, uma Orientadora Pedagógica e 08 professoras. Duas delas possuem Pós-Graduação em Psicopedagogia e as demais apenas são graduadas em Pedagogia. A diretora, a orientadora Pedagógica e a professora do $5^{\circ}$ ano foram nossas interlocutoras mais diretas.

Apresentadas as escolas e os sujeitos da nossa investigação, passemos a discutir nosso objetivos, procedimentos, bem como a apresentação e discussão de alguns achados. A pesquisa objetivou captar a percepção dos sentidos e efeitos que as avaliações externas, em especial da Prova Brasil, têm promovido no contexto escolar e no desenvolvimento do trabalho docente. Para nossa reflexão, algumas questões nos direcionaram: de que forma os testes estandardizados e o foco em resultado tem afetado a prática pedagógica docente no cotidiano escolar? Que mudanças os testes aplicados para aferir o nível de desempenho dos alunos têm provocado na organização do trabalho pedagógico, nas metodologias e nas aprendizagens dos alunos, tendo a qualidade como horizonte? Que indícios apontam para dimensões regulatórias/emancipatórias outras potencializadoras de uma proposta alternativa de avaliação voltada para o desenvolvimento da escola, dos professores e dos alunos?

Inicialmente, refletimos sobre as intersecções que ocorrem entre avaliação e qualidade como ponto de partida para compreender como o discurso da qualidade é apreendido e ressignificado no cotidiano escolar. Em seguida, discutimos algumas referências relativas aos conceitos de regulação, responsabilização e performatividade como tecnologias políticas a serviço das lógicas meritocráticas nas escolas. Por fim, procura-se contribuir para uma maior problematização destes efeitos, considerando-se as limitações dos testes e de seus resultados como definidores da qualidade da educação, apagando e desconsiderando processos vividos pelas escolas. Apresentar uma atitude propositiva e potencialidades de se constituir experiências de avaliação formativa e de construção da qualidade social da educação no espaçotempo das escolas é, também, necessário.

11 O município, segundo o Censo IBGE 2010, possuía uma população de 796.257 habitantes. A estimativa para 2015 é de 807.492 habitantes. Sua extensão territorial é de 521,249 Km². A rede municipal de educação conta com 106 escolas de ensino fundamental e aproximadamente 1.800 docentes. 


\section{Avaliação e qualidade: enquadramentos em busca de metas, apenas?}

Avaliação e qualidade são conceitos de múltiplos sentidos e de uma amplitude razoável. Apesar das tentativas de naturalizá-los com significados únicos, revestemse de complexidade e de caráter polissêmico, com finalidades e interesses diversos. Os discursos sobre a qualidade da escola pública e a necessidade de uma estrutura de produção de testes para aferir resultados assumem perspectivas que privilegiam acepções veladas e explicitadas sobre suas intencionalidades fazendo parecer que há uma ampla consensualidade.

Fernandes e Nazareth (2011) apontam que a grande relevância dada aos problemas da má qualidade da educação, evidenciados pelos resultados dos testes, não permite que se faça uma discussão prudente sobre a qualidade pretendida para nossas escolas, acarretando reflexões superficiais e enviesadas sobre a escola que queremos e defendemos. Assim, o discurso da qualidade envolve-se de retórica conservadora em contraposição com a visão de democracia e participação. Ancorase numa versão mercantil importada da economia, do mundo empresarial (Silva, 2009).

Os exames fazem parte das estratégias racionalizadas para definir o que se compreende como qualidade na perspectiva mercadológica. Em tempos de políticas educacionais de corte neoliberal, eles tornaram-se instrumentos racionalinstrumentais para definir desempenhos baseados numa pretensa exatidão, indicando os níveis de proficiência definidos centralmente e indicando o que é ou não qualidade. Para Silva (2009), pretende-se demonstrar que a ideia de qualidade, na perspectiva econômica, utiliza de parâmetros de comparabilidade, lançando mão de medidas, padrões, testes, rankings próprios do mercado

Os exames, em sua origem, destinavam-se à seleção e classificação dos melhores soldados e dos melhores funcionários públicos, como justificativa para evitar as ameaças de ocupação de cargos por laços familiares ou outras formas de clientelismo (Fernandes, 2009; Díaz Barriga, 2008; Dias Sobrinho, 2003). Para Afonso (2000), eles encontram seu ápice no período de ascensão e consolidação da burguesia que busca impor formas de seleção que levem em conta o mérito, competência atingida nos estudos, em substituição aos critérios baseados na herança aristocrática. A partir daí, expandiram-se e tornaram-se centrais na definição de competências e conhecimentos, constituindo-se em instrumentos que, supostamente, garantem objetividade, isenção e neutralidade na configuração de hierarquias e classificações.

O uso dos exames ajusta-se ao delineamento da organização científica do trabalho, articulada ao desenvolvimento do modo de produção capitalista. Os testes são 
reflexos do taylorismo, em que a competitividade, a hierarquia, a uniformidade e padronização de desempenhos individuais ficam evidentes a partir da intenção de padronizar comportamentos e ações. Isto representa a implementação de uma espécie de maquinaria da avaliação que lembra o papel dos eficientes engenheiros na época da organização científica do trabalho." (Afonso, 2000, p. 33).

A obsessão pelos exames, ou o que alguns insistem em nos confundir como avaliação, serve para atingir uma educação de qualidade conforme enquadres meritocráticos. Esta lógica de substituir "os exames" por "avaliação" induz à construção de um regime de verdade para indicar o que é e o que não é uma "escola de qualidade", constituindo uma "dada verdade", um pensamento hegemônico incontestável que ignora a diferença, a possibilidade de pensamento outro. O exame, assim, transformou-se em instrumento central para melhorar os sistemas de ensino e, portanto, conferir qualidade à educação. Não à toa estes são tempos de "delírios avaliatórios".

A avaliação reduz-se a uma visão simplista e alinha-se à ideia, também reducionista, de que a qualidade se manifesta em estatísticas e índices. Ela reveste-se do caráter objetivo, técnico e instrumental, materializado nos testes objetivos, com vistas a quantificar e classificar os produtos da aprendizagem, tornando-se, portanto, sinônimo de examinar. Alguns relatos mostram que os testes, por si só, são insuficientes para definir a qualidade de uma escola.

Não precisamos de mais provas, precisamos de melhores condições para desenvolver nosso trabalho, de tempo para planejar as aulas e para formação continuada de nossas professoras. Além disso, precisamos de tranquilidade para desempenhar melhor nossa tarefa. Aqui, por exemplo, é difícil termos paz. Sempre há confronto entre a polícia e os traficantes. Muitas vezes, quando o clima tá quente (sic), a gente precisa suspender as aulas. Como ter um educação de qualidade se há sempre interrupções? Se tivéssemos tranquilidade, policiamento, paz, conseguiríamos ter qualidade. Isso é que faz melhorar a escola! Parece que só o que importa é o resultado, o índice final. (Diretor, DC)

Para mim, a Prova Brasil não faz a menor diferença. Acho que seria mais interessante se nós tivéssemos mais tempo para a formação, que fizéssemos atividades para avaliar melhor. Para mim, os índices não dizem nada. [...] Não entendemos o que eles querem dizer. Nós sabemos que nossa escola vai bem. Tem um ideb melhor do que muitas escolas do município, mas não sabemos os que os dados querem dizer [...] (Professora, $\mathrm{NI})$

Os exames e seus resultados, exaustivamente defendidos como necessários para aferir a qualidade do sistema educativo brasileiro, produz efeitos diversos e perversos sobre os sistemas, sobre as escolas e, especialmente, sobre o trabalho de professores e professoras. O conceito de qualidade que defendemos não pode prescindir da ideia de que há fatores intra e extraescolares que interferem 
diretamente na qualidade da escola. Conforme Silva (2009), fatores socioeconômicos, socioculturais, financiamento público adequado e compromisso dos gestores centrais são determinantes externos que podem contribuir para constituir uma referência afirmativa de qualidade social da educação. Isso implica o cuidado com a segurança ao redor das escolas. Os fatores intraescolares também não podem ser negligenciados: tempo destinado para a organização do trabalho pedagógico, para o planejamento, para o atendimento à comunidade, gestão democrática, projetos interdisciplinares, acolhimento e participação da família na escola, ambiente solidário e de respeito às diferenças; inclusão; diálogo; trabalho coletivo e colaborativo; funcionamento efetivo dos conselhos de escola; avaliação formativa, interna e participativa. As intrínsecas relações entre os fatores intra e extraescolares para a qualidade da escola são percebidas pelos profissionais que atuam diretamente na escola:

Como nossa escola está próxima de uma comunidade violenta e nossos alunos são, na maioria, de lá, nós vivemos muitas tensões. As crianças não dormem direito porque muitos dos picos de violência acontecem durante a noite. Eles chegam à escola contando o que aconteceu. Tiros, confronto entre facções do tráfico ou com a polícia. Então, isso dificulta muito a aprendizagem deles. Quando chegam, estão agitadíssimos! Quando a gente senta para fazer a rodinha e contar as novidades, eles contam quem morreu, quem foi preso. (Professora 2, DC)

Na próxima seção, discutiremos algumas referências relativas aos conceitos de regulação, responsabilização e performatividade como tecnologias políticas a serviço das lógicas meritocráticas nas escolas e que estão voltadas para a consecução de uma qualidade que desconsidera estas relações entre os aspectos externos e internos à escola.

\section{Regulação, performatividade e responsabilização: efeitos no contexto escolar}

No Brasil, a proliferação de exames como sinônimos de avaliação é notória. Nos sistemas estaduais e municipais, sob um efeito replicante, há uma verdadeira disseminação do modelo central de avaliação que indica características regulatórias e de maior controle com intenções explícitas de transformar a educação num grande mercado (Afonso, 2010; Ball, 2005; Díaz Barriga, 2009; Dias Sobrinho, 2003).

Barroso (2005), em sua revisão sobre o conceito de regulação, expõe a polissemia do termo, estabelecendo relações muito próximas aos sentidos de controle, do estabelecimento de normatizações, de ajustes, de adequações aos padrões definidos centralmente. Em seu estudo, considera que seria mais prudente falar em 
"multirregulação", ao invés de considerar apenas o conceito de regulação. Nessa perspectiva, a regulação compreende processos múltiplos, contraditórios e, por vezes, conflituosos das ações dos sujeitos.

O direito à aprendizagem e a busca pela qualidade da educação são justificativas que servem para delinear um discurso assentado numa política de avaliação sistêmica que tem servido muito mais para a regulação, controle da gestão e do trabalho docente e para mensuração de desempenhos. Nesta lógica, os exames por si só garantem confiabilidade, legitimidade e fidedignidade técnica para definir as performances da escola, do docente e definir por meio de um índice a sua qualidade.

Para Ball (2004, p. 1106), os movimentos de reforma surgem "de mudanças nos papéis do Estado, do capital, das instituições do setor público e dos cidadãos e nas suas relações entre si [...]". As mudanças se dão, inicialmente, no movimento de passagem "do Estado como provedor para o Estado como regulador, estabelecendo as condições sob as quais vários mercados internos são autorizados a operar." (Ball, 2004). A partir daí, um conjunto de ações desencadeia-se para tornar o Estado eficiente, eficaz e ágil: avaliação de desempenho de alunos, responsabilização de escolas e professores, implantação de políticas de bonificação/premiação docente, redefinição das funções de gestores, etc. Apesar de muito semelhantes, as políticas de avaliação não assumiram características uniformes nos diversos países, mas apresentam alguns aspectos comuns: neoconservadorismo na educação, foco em desempenhos, estreitamento curricular, competição entre professores e escolas, ausência da dimensão pedagógica e exacerbação da dimensão técnica, preparação para os testes (Freitas, 2012).

A inserção de uma cultura gerencialista de cunho empresarial no setor público promoveu uma verdadeira invasão de instrumentos de regulação, performances e responsabilização. A avaliação em larga escala, pautada no estabelecimento de indicadores para medir desempenhos dos alunos, performances das escolas e de seus professores, torna-se mecanismo essencial para legitimar o controle do trabalho docente em resultados aferidos nos testes padronizados e se sustenta numa cultura racionalista de constituição de standards, que medem e estabelecem metas para serem atingidas, "com ênfase nos processos de gerenciamento da força de trabalho da escola (controle pelo processo, bônus, punições), ancorada nas mesmas concepções oriundas da psicologia behaviorista, fortalecida pela econometria, ciências da informação e de sistemas, elevado à condição de pilares da educação contemporânea." (Freitas, 2012, p. 383). Dessa forma, meritocracia, responsabilização, privatização, qualidade, eficácia, eficiência, performance, competência e testes compõem o amplo espectro lexical da competitividade e da lógica empresarial na educação (Afonso, 2010; Freitas, 2012; Pacheco, Pestana, 2014).

O caráter psicométrico dos exames garante a padronização dos procedimentos 
avaliatórios e a homogeneização das condições de respostas aos testes, o que significa homogeneizar também o currículo e os comportamentos dos sujeitos submetidos a ele. Nestas condições, nega-se a possibilidade das diferenças entre sujeitos, estados, regiões, localidades, etc. Estabelece, portanto, uma ampla uniformização em todo o território nacional. Para Esteban (2012), a avaliação, nestes termos, assumese como força impositiva de reconhecimento daqueles que se encontram dentro de determinado padrão. Aqueles que se afastam são desqualificados, apagados e excluídos. A eficácia e eficiência exigidas das escolas e dos docentes evidenciam as novas funções a serem assumidas, impondo uma autoimagem que desvaloriza as suas particularidades. Alguns relatos ilustram de forma bastante evidente essas características:

[...] os professores têm se esforçado muito para melhorar os resultados, mas, quando os resultados são divulgados, há um cenário desolador. A frustração é clara no rosto de todas aqui da escola. (Diretora de Escola, NI).

Tem ainda a pressão externa para melhorar o Ideb. A Secretaria está cobrando sim. Quando fica mais próximo da Prova Brasil, mais o cerco se aperta pra gente preparar as crianças. (Professora 1, DC)

Fizemos duas reuniões para discutir os resultados do IDEB de 2011. Fizemos uma autoavaliação e procuramos entender o que houve, quais foram as nossas falhas, mas o sentimento de frustração foi muito maior e não conseguimos entender quais foram as nossas fragilidades e ninguém nos ajudou a entender. Isto é injusto com a gente, pois não somos avaliados nas nossas condições reais. (Diretora Escola, $\mathrm{NI})^{12}$

A cultura da performatividade, na qual o docente é protagonista e é convocado a apresentar desempenhos cada vez mais eficazes e eficientes (Ball, 2004, 2005, 2011) pauta as ações dos indivíduos e das instituições. Neste contexto, a avaliação é processo privilegiado de controle para atingir metas, a efetividade e a qualidade, criando uma lógica performativa do trabalho docente. A intensificação do trabalho, em busca de melhores resultados é a materialização dessa "corrida performativa". Exemplos dessa intensificação mostram-se nestes relatos:

Não faço mais nada além de preparar para a Prova Brasil. Na escola, fazemos simulados todo mês. Tem sido muito estafante porque a gente tem que elaborar os simulados, corrigir, preencher fichas. (Professora 1, DC)

Me sinto muito cobrada e pressionada para melhorar a nota na Prova Brasil. Estou trabalhando muito, pois muitos alunos têm grandes dificuldades em leitura e

${ }^{12}$ Referência aos resultados de 2011, tendo em vista que este dado foi colhido no primeiro semestre de 2012. 
interpretação. Este ano, como vai ter Prova Brasi ${ }^{13}$, tudo tem que estar voltado pra ela. O problema é que estes resultados não levam em consideração a realidade que enfrentamos aqui. É tiroteio, é conflito, é medo [...] É evasão do aluno porque a família se muda por causa do tráfico [...] É muito frustrante não poder fazer um trabalho de qualidade. (Professora 2, DC)

Aperformatividade éalcançada quando são construídos e disseminados indicadorese informações que permitam a publicidade de escolas, como instrumentos de estímulo, julgamento, premiação, punição e comparação entre profissionais e instituições. Isto se dá na ampla divulgação de resultados nas avaliações em larga escala, o que produz a elaboração de rankings, exaltando as primeiras colocadas, consideradas escolas melhores e de qualidade; e as demais como incompetentes, ineficientes e sem qualidade. A forma como são divulgados os resultados, principalmente pela grande imprensa, acaba interferindo e condicionando diretamente as práticas pedagógicas dos profissionais, gerando efeitos de considerável pressão sobre o trabalho docente. Ao ser pressionado pelos resultados, professores tornam-se "treinadores para os testes", o que contribui, incisivamente, para sua desprofissionalização.

Meu trabalho está muito limitado. Me sinto presa. Nas semanas antes da Prova Brasil, eu só trabalho com Português e Matemática porque é o que vai ser cobrado. As crianças ainda participam do reforço. Fazemos simulados para que eles se familiarizem com as questões, mas às vezes, acho que é muito excesso de testes [...]. (Professora 3, DC)

A Secretaria preparou um simulado para ver se os alunos estão preparados para a Prova Brasil. Eu não tenho tido tempo para mais nada. O ano está acabando, mas o foco é só nesta prova. Às vezes eu me pergunto: o que estamos ensinando para nossos alunos? A marcar "xizinho" numa prova? Parece que meu trabalho se resume a isto [...] Fico triste. Me sinto desmotivada. (Professora 1, NI)

Estudos e pesquisas recentes (Amaro, 2013; Assumpção, 2013; Mota, 2013; Lino, 2014; Melo, 2014), que tomam as escolas das periferias como campo, apontam que a cultura do exame invadiu, de forma contumaz e insistente, o cotidiano da escola, alterando práticas, fazeres, saberes e as funções docentes. Constatam que há um cenário bastante preocupante associado aos aspectos apresentados por Freitas (2012): estreitamento curricular, competitividade entre docentes e escolas, preparação e treinamento para os testes, cobranças pelo alcance de metas e desempenhos, precarização do trabalho docente, dentre outros.

Esta dinâmica cria, cada vez mais, um processo de responsabilização dos docentes, pais, alunos e da escola pelos resultados, retirando todo e qualquer compromisso do Estado com a qualidade da escola pública. O foco na responsabilização de escolas e

\footnotetext{
${ }^{13}$ Referência a Prova Brasil a ser aplicada no final do ano de 2011, período em que as entrevistas foram realizadas nesta escola.
} 
seus docentes no sucesso ou fracasso dos alunos nos testes estabelece um cenário de "falsa descentralização", pois o Estado exime-se de qualquer responsabilidade sobre a infraestrutura das unidades escolares e transfere para os sujeitos da ponta toda a carga de compromisso pela "aprendizagem" ou "não aprendizagem" dos alunos, independentemente dos contextos, das diferenças e situações vivenciadas no cotidiano.

$\mathrm{Na}$ tentativa de vislumbrar compromissos assumidos coletiva e horizontalmente, sem isentar o Estado da sua responsabilidade de prover os sistemas para que se construa uma qualidade social da educação, discuto, a título de conclusão, algumas potencialidades de práticas avaliativas articuladas à necessidade de uma "accountability alternativa" (Afonso, 2012) que esteja voltada para o desenvolvimento da escola, de seus docentes e de seus alunos em amplos processos de negociação coletiva.

\section{A título de conclusão: caminhos avaliativos outros são possíveis...}

Após mais de 20 anos de avaliação, o cenário educacional ainda é pouco alentador em relação à qualidade. Persistem, ainda, graves problemas nas escolas que envolvem aspectos infraestruturais, altos índices de reprovação, defasagem idade/série, evasão, falta de material, gestões escolares atreladas a poderes políticos locais, projetos e programas desarticulados e sobrepostos, formação insuficiente dos professores, dentre outros. Esses problemas afetam diretamente a qualidade e não podem ser enfrentados com exames para aferir desempenhos. Se as informações que são produzidas nestas avaliações não são apropriadas, analisadas e discutidas profundamente pelos sistemas, dificilmente estes problemas poderão ser superados.

A avaliação de escolas provoca tensões e sentimentos negativos. A pressão sofrida pelos docentes para atingir as metas e os resultados impõem uma lógica perversa baseada no medo: de não alcançar metas, de ser considerado incompetente, de ser punido, de ser culpado, responsabilizado. Pode culminar em desmotivação, stress, descontentamentos, acúmulo de funções, o que provoca uma sobrecarga de trabalho. Se os profissionais docentes não se reconhecem como pensadores e participantes das decisões relativas à organização escolar, ao currículo, às práticas pedagógicas e, naturalmente, à avaliação, obstáculos podem surgir para o alcance dos objetivos e funções educativas em sua integralidade. Toda e qualquer ação e ou política tem maior potencialidade se integrada à instituição, de forma coparticipativa, corresponsável, coletiva e num clima de confiança e pertencimento.

Diante disso, cabe perguntarmos: não há espaços de negociação e de construção de 
formas alternativas de avaliação?

Se conduzidas com estratégias participativas, coletivas e não conformadas numa perspectiva reducionista de formação, as avaliações podem fornecer informações relevantes sobre o desempenho dos alunos, sobre o trabalho dos professores, sobre suas condições de trabalho, sobre o funcionamento da escola e sobre sua estrutura, desde que ancoradas em princípios éticos e políticos de corresponsabilidade, subsidiando políticas públicas de reversão dos problemas que afligem cada unidade escolar.

De acordo com Sordi (2012, p. 487), não se trata de desconsiderar a necessidade do uso de informações de medida como elementos da avaliação, mas trata-se de compreendê-las como insuficientes e destinadas a outras finalidades, acionando uma complexa rede interpretativa e problematizadora. É necessário que os movimentos reais que acontecem na escola e que as informações produzidas pelas avaliações externas possam ser tomadas como indicadoras para a apropriação de seus problemas, a partir do diálogo constante com práticas cotidianas da avaliação interna, propiciando um ambiente reflexivo da instituição escolar, levantando e definindo outros indicadores que não se restrinjam ao desempenho dos alunos e ao fluxo escolar, apenas.

Para além destas políticas conservadoras, caminhos alternativos de responsabilização e de regulação da qualidade da escola pública que se constituam como reação aos modelos de avaliação centrados em resultados dos estudantes em testes padronizados são possíveis e necessários. Para Afonso (2010), pensar em alternativas de accountability, como possibilidade de uma concepção mais ampliada e complexa, faz-se fundamental. O autor defende uma configuração democrática de accountability que inclui a avaliação, a prestação de contas e a responsabilização como elementos abertos, problematizáveis e disponíveis para se aperfeiçoarem, sustentados em aspectos éticos, cidadãos, participativos, coletivos, focalizados no direito à informação, à transparência e à justiça. Dessa forma, a avaliação da escola vai além da lógica empresarial e meritocrática imposta. Ela deve assumir potencialidades alternativas que envolvam uma "accountability" inteligente, alternativa e negociada. (Afonso, 2012; Sordi, 2012; Bondiolli, 2004)

Por fim, os projetos de avaliação alternativos que tomem a escola e seus docentes, bem como os demais sujeitos, como centros de referência para discutir, problematizar e pronunciar-se sobre o tipo de qualidade que almejam (Lino, 2014) podem se transformar em instrumentos de contrarregulação. A avaliação, seja ela externa, interna ou da aprendizagem, deve fazer parte do processo pedagógico articulando objetivos e finalidades da educação, com os pressupostos da avaliação formativa (Amaro, 2011, 2013). A lógica dos exames não contribui para o desenvolvimento e avanço da qualidade das escolas, das aprendizagens e do trabalho docente e, muito menos, contribui para uma educação pautada na diferença e na pluralidade. Somente 
fundados na perspectiva de avaliar, formativamente, é que se pode pensar em processos compartilhados e participativos de melhoria da qualidade da educação.

\section{Referências}

AFONSO, Almerindo J. Para uma conceptualização alternativa de accountability em educação. Educ. Soc., Campinas, v. 33, n. 119, p. 471-484, abr.-jun. 2012

. Um olhar sociológico em torno da accountability em educação. In: AFONSO, Amerindo J. ESTEBAN, Maria Teresa. (orgs.). Olhares e interfaces: reflexões críticas sobre a avaliação. São Paulo: Cortez, 2010.

. Estado, políticas educacionais e obsessão avaliativa. Contrapontos, v. 7, n. 1, p. 01-22, Itajaí, Jan./Abr. 2007.

Avaliação educacional: regulação e emancipação. São Paulo: Cortez, 2000.

AMARO, Ivan. Avaliação externa da escola: repercussões, tensões e possibilidades. Est. Aval. Educ. São Paulo, v. 24, n. 54, p. 32-55, jan./abr. 2013.

"O portfólio eletrônico na formação de professores: caleidoscópio de múltiplas vivências, práticas e possibilidades da avaliação formativa." In: VILLAS BOAS, B. M. de F. (org.). Avaliação formativa: práticas inovadoras. Campinas: SP, Papirus, 2011.

BALL, Stephen J. "Sociologia das políticas educacionais e pesquisa críticosocial: uma revisão pessoal das políticas educacionais e da pesquisa em política educacional." In: BALL, Stephen. J. MAINARDES, J. (Orgs.) Políticas educacionais: questões e dilemas. São Paulo: Cortez Editora, 2011.

Profissionalismo, gerencialismo e performatividade. Cadernos de Pesquisa, São Paulo-SP, n. 126, p. 539-564, set./dez, 2005.

Reformar escolas/reformar professores e os terrores da performatividade. Revista Portuguesa de Educação, año/vol. 15, número 002, Universidade do Minho, Braga, Portugal, pp. 3-23,2004.

BARROSO, João. O Estado, a educação e a regulação das políticas públicas. Educ. Soc., Campinas, vol. 26, n. 92, p. 725-751, Especial - Out. 2005. Disponível em: < http://www.cedes.unicamp.br>. Acesso em 20/10/2013. 
BERNARDES, D. A Baixada Fluminense nas páginas do jornal O Globo. Projetos experimentais.com, v. 1, $\mathrm{n}^{\circ}$ 1, p. 20-42, 2007.

BONDIOLI, Ana. (org.). O projeto pedagógico da creche e a sua avaliação: a qualidade negociada. Campinas-SP: Autores Associados, 2004.

CRUZ, Frederico Alan de Oliveira. Desempenho educacional e renda domiciliar: análise do Ideb dos municípios da Baixada Fluminense. Vivências, v. 8, $n^{\circ} 14, p$. 92-99, Mai. 2012.

DIAS SOBRINHO, José. Avaliação: políticas educacionais e reformas da educação superior. São Paulo: Cortez, 2003.

"Educação e avaliação: técnica e ética". In: DIAS SOBRINHO, J. RISTOFF, D. (orgs). Avaliação democrática: para uma universidade democrática. Florianópolis: Insular, 2002.

DÍAZ BARRIGA, Angel. A avaliação na educação mexicana: excesso de programas e ausência da dimensão pedagógica. Sísifo. Revista de Ciências da Educação, v. 9, pp. 19-30. Acesso em 20 mar. 2011] <disponível em http://sisifo.fpce.ul.pt>, 2009. 2008.

ENNE, A. L. S. Imprensa e Baixada Fluminense: múltiplas representações. Ciberlegenda, $n^{\circ}$ 14, 2004.

ESTEBAN, Maria Teresa. (Org.) . Avaliação: uma prática em busca de novos sentidos. 5. Ed., Petrópolis: DP et Alii, 2008a .

. Escola, currículo e avaliação. 3. Ed., Série Cultura, memória e currículo, v. 5, São Paulo: Cortez, 2008b

ESQUINSANI, Rosimar S. S. Performatividade e educação: a política das avaliações em larga escala e a apropriação da mídia. Práxis Educativa, Ponta Grossa, v.5, n.2, p. 131-137, jul.-dez. 2010. Disponível em http://www.periodicos.uepg.br. Acesso em 06 de setembro de 2013

FERNANDES, Domingos. Avaliar para aprender: fundamentos, práticas e políticas. São Paulo: Editora UNESP, 2009.

FERNANDES, Claudia. O. NAZARETH, Henrique D. G de. A retórica por uma educação de qualidade e avaliação em larga escala. Revista Impulso, PiracicabaSP. 21(51), 63-71, jan.-jun. 2011

FREITAS, Luiz Carlos de. Os reformadores empresariais da educação: da desmoralização do magistério à destruição do sistema público de educação. Educ. 
Soc., Campinas, v. 33, n. 119, p. 379-404, abr.-jun. 2012.

. SORDI, Mara Regina L. de. Responsabilização participativa. Revista Retratos da Escola, Brasília, v. 7, n. 12, p. 87-99, jan./jun. 2013.

PACHECO, José A.; PESTANA, Tânia. Globalização, aprendizagem e trabalho docente: análise das culturas de performatividade. Educação, Porto Alegre, impresso, v. 37, n. 1, p. 24-32, jan./abr.2014.

SHIROMA, Eneida. O. SCHNEIDER, Mara Cristina. Professores em exame: reflexões sobre práticas de avaliação docente. Práxis Educativa, Ponta Grossa, v.6, n.1, p. 31-44 , jan.-jun. 2011. Disponível em <http://www.periodicos.uepg.br. > Acesso em 06 de setembro de 2013.

SORDI, Mara Regina L. de. Implicações ético-epistemológicas da negociação nos processos de avaliação institucional participativa. Educ. Soc., Campinas, v. 33, n. 119, p. 485-510, abr.-jun. 2012.

VEIGA-NETTO, Alfredo. Currículo: um desvio à direita ou delírios avaliatórios. X Colóquio sobre Questões Curriculares e VI Colóquio Luso-Brasileiro de Currículo, 04/09/2012, UFMG, Belo Horizonte, MG. Disponível em: http://www.fe.unicamp. $\mathrm{br} /$ TEMPORARIOS/veiga-neto-curriculos-delirios-avaliatorios.pdf $>$. Acesso em 14 de abril de 2014.

WERLE, Flavia O. C. Políticas de avaliação em larga escala na educação básica: do controle de resultados à intervenção nos processos de operacionalização do ensino. Ensaio: aval. pol. públ. Educ., Rio de Janeiro, v. 19, n. 73, p. 769-792, out./ dez. 2011.Disponível em: < http://www.scielo.br/pdf/ensaio/v19n73/03.pdf>. Acesso em 20/03/2014.

\section{Recebido em agosto de 2015}

Aprovado outubro de 2015

Ivan Amaro é doutor em Educação pela Universidade Estadual de Campinas (Unicamp) e professor do Programa de Pós-Graduação em Educação, Cultura e Comunicação em Periferias Urbanas - PPGECC - FEBF/Universidade Estadual do Rio de Janeiro (UERJ).

E-mail: ivanamaro.uerj@gmail.com 